an C. Bickle, MB BCh BAO, FRCR'

Diyana Mohamed, $\mathrm{MBChB}^{2}$

'Department of Radiology

RIPAS Hospital,

Bandar Seri Begawan

Brunei

${ }^{2}$ Wellington School of Medicine, University of Otago New Zealand
Correspondence: Dr. lan C. Bickle

Department of Radiology

RIPAS Hospital

Bandar Seri Begawan BA1710

Brunei Darrusalam

Phone: (673) 8612182

Fax: (673) 2242690

Email: ian@bickle.co.uk

Reprints will not be available from the author.

The authors declared that this represents original material that is not being considered for publication or has not been published or accepted for publication elsewhere, in full or in part, in print or electronic media; that the manuscript has been read and approved by the authors, that the requirements for authorship have been met by the authors, and that the authors believe that the manuscript represents honest work.

Disclosures: The authors signed a disclosure that there are no financial or other (including personal) relationships, intellectual passion, political or religious beliefs, and institutional affiliations that might lead to a conflict of interest.

\section{Cerebral Abscess with Rupture into the Ventricles due to Chronic Otitis Media}

This 43-year-old man with a known history of schizophrenia presented with a one-week history of left ear pain accompanied by a purulent discharge from the external auditory canal over the last three days. Shortly afterwards he became confused.

On direct examination, the left ear canal was oedematous containing granulation tissue.

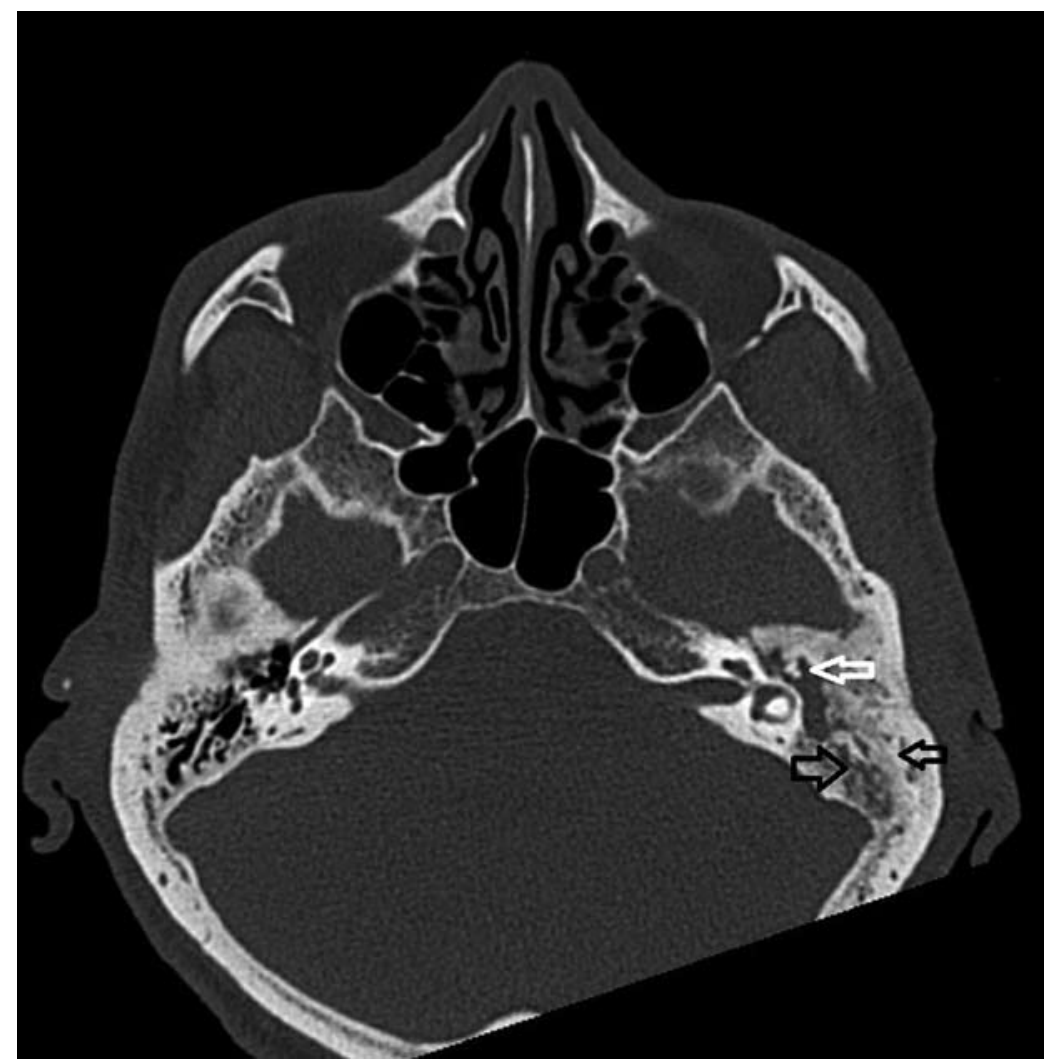

Figure 1. High resolution CT of Temporal Bone: Sclerosis of the temporal bone (thin black arrow) with pus in the mastoid air cells (wide black arrow). Soft tissue in the middle ear surrounding the ossicular chain (white arrow). 

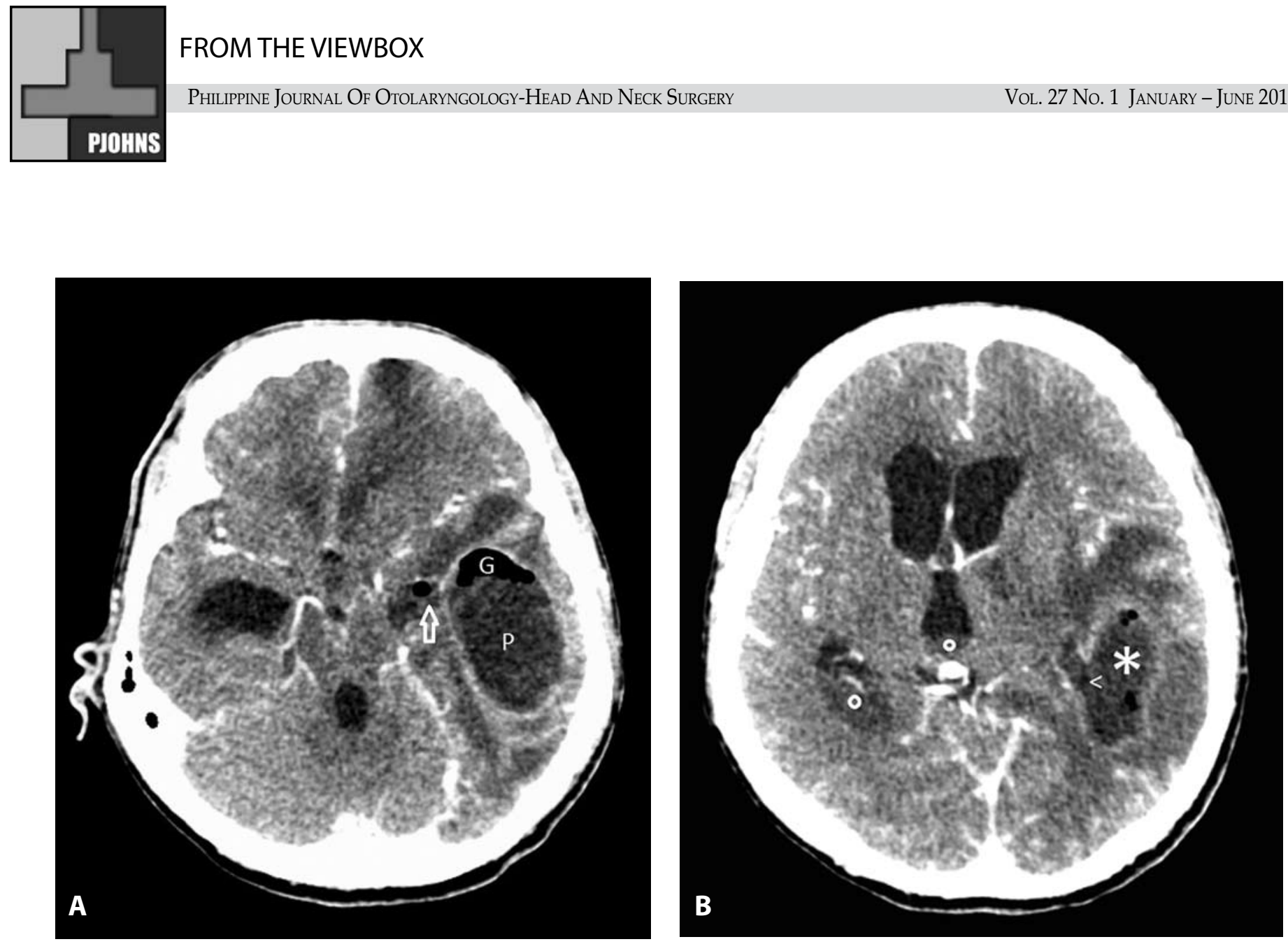

Figure 2. A. Contrast enhanced Axial CT of the Brain: a large left temporal lobe abscess containing pus (P) and gas (G), with similar content in the temporal horn of the left lateral ventricle (arrow). B. Left temporal lobe abscess (asterisk) with tract formation (arrow) communicating with the ventricle. Pus in the third ventricle and the right lateral ventricle (circles).

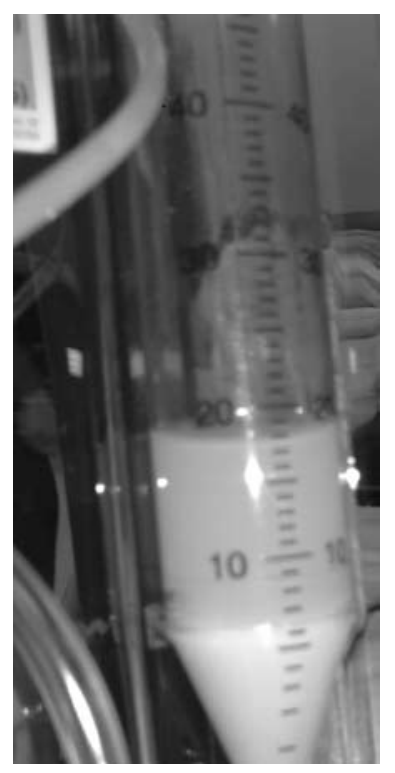

Figure 3. Pus contaminated CSF in the extra-ventricular drain
High resolution CT of the temporal bones supplemented by contrast enhanced CT of the brain was performed in this patient. This identified sclerosis of the left temporal bone with opacified mastoid air cells along with soft tissue within the middle ear. (Figure 1) Contrast enhanced $\mathrm{CT}$ of the brain established the presence of a large left temporal lobe abscess, with a tract communicating with the left lateral ventricle, which contained pus resulting in a tri-ventricular obstructive hydrocephalus. (Figures 2A\&B)

Severe intracranial complications of otitis media are uncommon but are associated with significant morbidity and mortality. The incidence of intracranial and intra-temporal complications of otitis media is reported at 3.2 per million, of which only $18 \%$ are intracranial in nature.' Of the intracranial complications cerebral abscess is the commonest occurring in nearly half of all cases. Typically, the bacteria causing the abscess are anaerobes. The annual risk in adults of developing a 
cerebral abscess secondary to otitis media is in the region of 1 in 10,000. ${ }^{2}$ Other intracranial complications include; venous sinus thrombosis, meningitis, extra-axial collections and hydrocephalus. A known, albeit rare, complication of cerebral abscess is rupture into the ventricular system. ${ }^{3}$ Obstructive hydrocephalus may then result.

A left temporal craniotomy and abscess excision was performed with insertion of an extra-ventricular drain which contained pus. (Figure 3) A modified radical mastoidectomy was then performed. The presence of gas within the intracranial abscess cavity is an indication for total surgical excision of the abscess as it allows removal of the mass lesion, prevention of possible persistent extra-corporal communication and provides debridement of devitalised tissue that might prevent resolution of infection. ${ }^{4}$

In this case, the diagnosis of brain abscess was delayed as his psychiatric history distracted from the history of confusion. This serves as a learning point for us all in our clinical endeavours.

REFERENCES

1. Leskinen K, Jero J. Acute complications of otitis media in adults. Clin Otolaryngol. 2005 Dec; 30(6):511-516.

2. Nunez DA, Browning GG. Risks of developing an otogenic intracranial abscess. J Laryngol Otol.1990 Jun;104(6):468-472

3. Dähnert W. Radiology Review Manual. 5th ed. Baltimore MD and Philadelphia PA: Lippincott Williams \& Wilkins; 2003. p257.

4. Young RF, Frazee J. Gas within intracranial abscess cavities: an indication for surgical excision. Ann Neurol. 1984 Jul;16(1):35-39. 